\title{
Effects of High Slag Accumulation on the Stability of Underground Tunnels
}

\author{
Gui-Wu Han \\ Department of Crossing, China Petroleum Pipeline \\ Engineering Corporation; No 146 \\ Heping Road, Guangyang District, Langfang, China \\ hanguiwu@cnpc.com.cn \\ Yin Li \\ Department of Crossing, China Petroleum Pipeline \\ Engineering Corporation \\ Heping Road, Guangyang District, Langfang, China \\ liyin@cnpc.com.cn
}

\author{
Liu-Zheng Liang \\ Department of Crossing, China Petroleum Pipeline \\ Engineering Corporation; No 146 \\ Heping Road, Guangyang District, Langfang, China \\ liangjiuzheng@cnpc.com.cn
}

\begin{abstract}
In this paper one underground storage cavern's stability is studied, on the condition of high-piled-slag right over the tunnels. The finite element software ANSYS is used as a tool solving the overlying loads's effects to underground rock mass. The calculation results show that, due to the reason that surrounding rock is slightly weathered hard granite and self stabilization ability is strong, the overlying load on the maximum combined stress value of tunnel effect is small.
\end{abstract}

Keywords-Slag heap height; Underground cavern; Rock stability; Underground stress ; FEM.

\section{INTRODUCTION}

It is dangerous to accumulate piles of slag stone on top of underground caves. But in some projects, due to the limitation of the site, it is inevitable to pile slag on the top of the tunnel. This paper takes one large underground project as a case, to study the effects of temporary accumulating slag to undergrounds' cavern stability.

\section{PROJECT BRIEF}

One underground oil storage caverns is located in the northeast of China, with reserves designed $300 \times 104 \mathrm{~m} 3$. Considering the tunnel over break and loose coefficient, the actual slag residue may be larger than $450 \times 104 \mathrm{~m} 3$. In the construction process due to problems of coordination with local government, It is failed to find one appropriate position for slag. The slag stone excavated from underground right piled up on the top of caverns, the slag heap height of about $25 \sim 30 \mathrm{~m}$.

\section{A. Formation characteristics.}

According to field drilling, the bedrock includes coarse grain granite, interspersed with diabase, angle of diorite porphyrite and fine grained rock dike. The stratum distribution is more complicated, and rock veins are interspersed. According to weathering degree and integrity, the formation of the field area is as follows:
1) Residual soil: All the original rock structure was destroyed and weathered into a soil like, with layer thickness of $0.50 \sim 6.00 \mathrm{~m}$.

2) Fully weathered layer: Mainly brown coarse grain granite and clay like diabase, Structural elements basically damaged, with residual structure little strength.

3) Strongly weathered layer: It consists of coarse grain granite, gray green diabase, black diorite porphyrite and shallow red coarse-grained granite, blocky rock mass structure, with layer thickness $0.20 \sim 36.15 \mathrm{~m}$.

4) Middle weathered layer: Mainly in coarse grain granite and partly Granitic rock and diabase, massive structure and partly structure failure, with layer thickness 0.10 $37.44 \mathrm{~m}$.

5) Weak weathered layer: Mainly in coarse grain granite and partly Granitic rock and diabase, block rock mass formation and RQD value between 75\% 90\%, with layer thickness $0.32 \sim 24.01 \mathrm{~m}$.

6) Not-weathered layer: Mainly in coarse grain granite and partly Granitic rock and diabase, block rock mass formation, relatively complete rock mass structure, and RQD value between 75\% 100\%, with unknown layer thickness.

\section{B. Physical and mechanical parameters.}

The main caverns are located below the surface of the planet below $80 \mathrm{~m}$ position, and mainly in not-weathered layer. According to survey and geologic references, the rock physics mechanics parameters in not-weathered layer are shown as table.1Considering the rock mass characteristics are the following: the rock density is $2.7 \times 103 \mathrm{~kg} / \mathrm{m} 3$, the elastic modulus is $9 \mathrm{GPa}$, and the Poisson's ratio is taken to 0.2 .

\section{Underground stress distribution.}

Site stress tests were carried out, and report shows the maximum horizontal principal stress is $6.19 \sim 11.50 \mathrm{MPa}$, 
the minimum horizontal principal stress is $3.63 \sim$ 9.02MPa, and the vertical principal stress is $1.81 \sim 3.61 \mathrm{MPa}$.

\section{FEM CALCULATION}

\section{A. FEM Modal hypothesis}

1) Setup plan strain model, taking rock mass as a continuum, and ignoring the fracture of joints in rock.

2) The stack of slag's load is uniformly applied to the underground tunnel, and tunnel's deformation is mainly influenced by the slag's load and underground stress.

3) Tunnels can self-control stability, the reinforcement lining is ignored and the calculation results are conservative.

\section{B. Boundary and load settings}

Modal boundary. Usually in geotechnical engineering, rock cavern spans 3 to 5 times the range as the study object.
In this modal, the thickness of overload layer is $80 \mathrm{~m}$, and 4 times of tunnel wideness is taken.

Load. Vertical load comes from overburden rock layer and overload stack slag. The overburden rock layer is $80 \mathrm{~m}$ rock's weight, and the overload stack slag is 30m slag's weight. Horizontal load comes from horizontal underground stress, and according to in-situ stress survey, the horizontal underground stress is 4 times of the vertical underground stress. In the FEM modal, vertical load is been achieved by density setting gravity acceleration setting, and horizontal load is been achieved by gradient pressure setting.

Boundary constraints. Two faces are thinking about, one is the bottom line's vertical displacement constraints is zero, another is central line's horizontal displacement constrains is zero. For the FEM model is symmetrical, it can take half of the rock mass as study object to reduce computational resources.

TABLE I. Physical and Mechanical Parameters of Rock Mass

\begin{tabular}{|c|c|c|c|c|c|c|}
\hline \multicolumn{2}{|c|}{$\begin{array}{l}\text { Physical and } \\
\text { mechanical } \\
\text { parameters }\end{array}$} & $\begin{array}{l}\text { Uniaxial } \\
\text { tensile } \\
\text { strength /MPa }\end{array}$ & $\begin{array}{l}\text { Uniaxial } \\
\text { compressive } \\
\text { strength /MPa }\end{array}$ & $\begin{array}{l}\text { Elastic } \\
\text { modulus /GPa }\end{array}$ & $\begin{array}{l}\text { Poisson } \\
\text { ratio }\end{array}$ & $\begin{array}{l}\text { Shear } \\
\text { modulus } \\
/ \mathrm{GPa}\end{array}$ \\
\hline \multirow{2}{*}{ Granite } & section & $7.29 \sim 9.45$ & $150.15 \sim 193.41$ & $36.94 \sim 38.76$ & $0.18 \sim 0.22$ & I \\
\hline & average & 8.60 & 174.37 & 38.05 & 0.20 & 15.80 \\
\hline \multirow{2}{*}{$\begin{array}{l}\text { Granitic } \\
\text { rock }\end{array}$} & section & $11.10 \sim 13.01$ & 86.97 273.17 & $31.33 \sim 35.25$ & $0.10 \sim 0.14$ & I \\
\hline & average & 12.19 & 168.85 & 33.49 & 0.13 & 14.80 \\
\hline \multirow{2}{*}{ Diabase } & section & 7.89 17.56 & $157.65 \sim 184.68$ & $43.35 \sim 52.72$ & $0.11 \sim 0.26$ & I \\
\hline & average & 13.11 & 172.16 & 48.69 & 0.18 & 20.56 \\
\hline
\end{tabular}
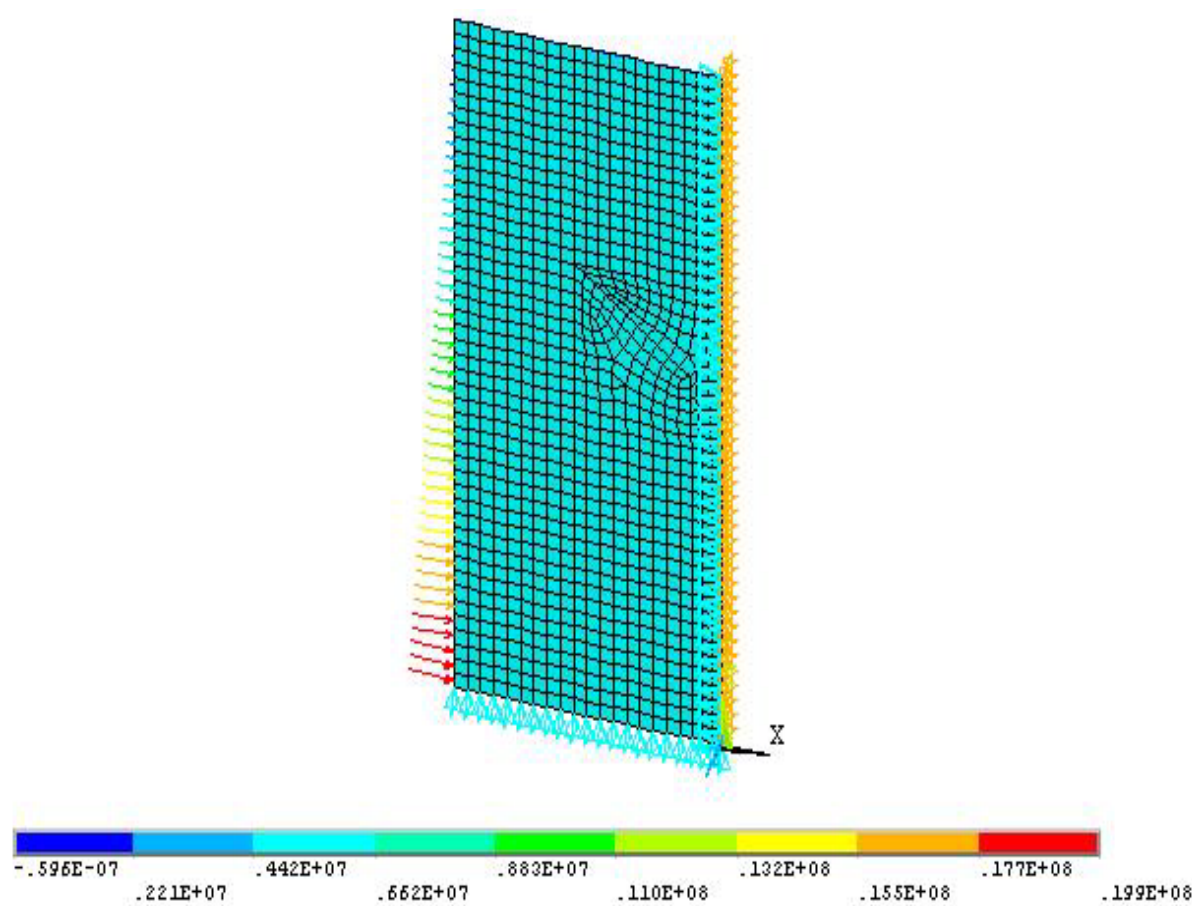

Figure 1. Modal meshed with constraints and loads 


\section{Calculation result}

The results of two kinds of working conditions have been calculated. The stress distributions of rock mass make differences between before slag- piled condition and after slag- piled condition.

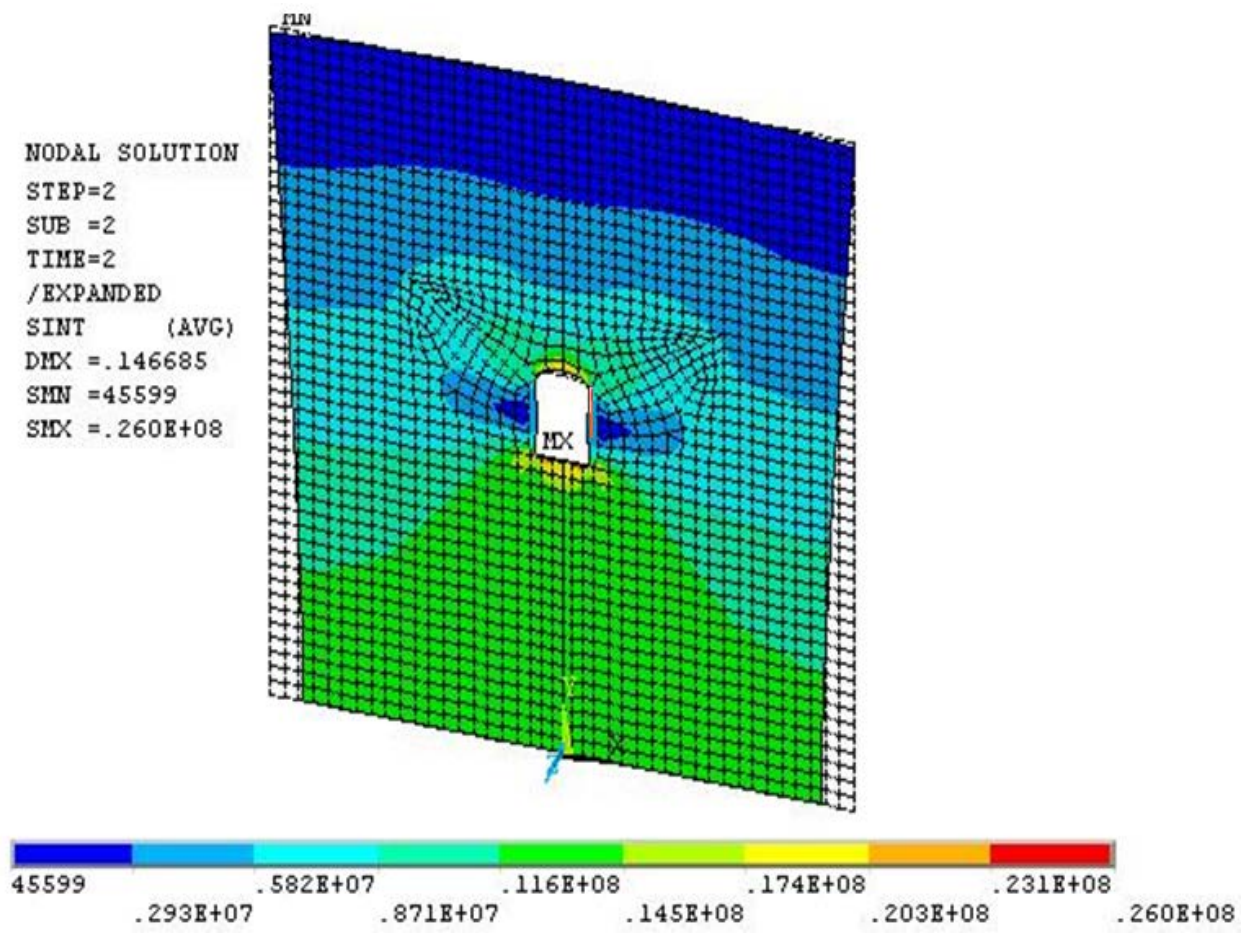

Figure 2. Stress distribution of before slag-piled condition (Pa)

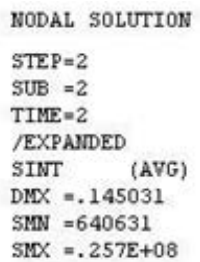

$\operatorname{SMX}=.257 \mathrm{E}+08$
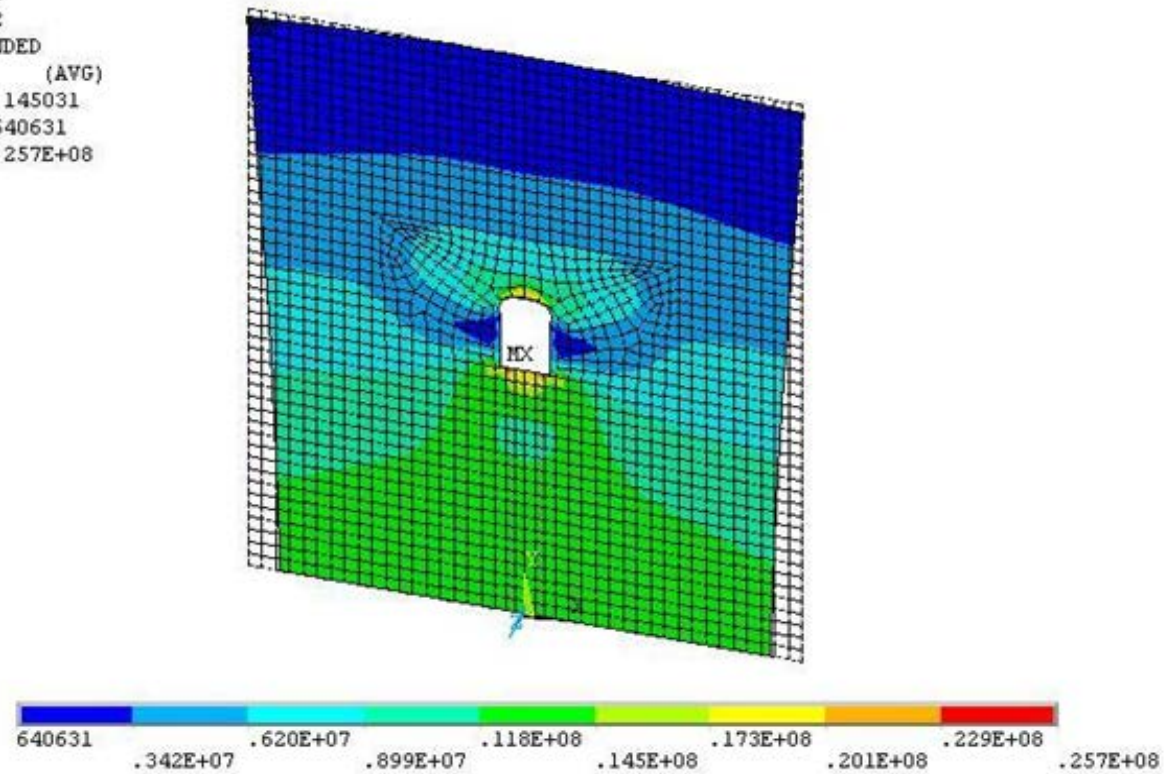

Figure 3. Stress distribution of after slag-piled condition (Pa) 


\section{CONCLUSION}

Based on the above calculation results, the following conclusions can be drawn.

1) The maximum stress is located at the bottom cavern floor, but it will not affect the structure of the cavern.

2) By comparison, the maximum stress of before slag-piled condition is $26 \mathrm{Mpa}$, and the maximum stress of after slag-piled condition is $25.7 \mathrm{MPa}$. So the slag's piled effect to underground cavern stability is very gentle.

3) In theory, the stack of slag-piled adds the minimum underground stress $\sigma_{3}$ value, but the $\sigma_{1}$ unchanged, so the value of $\sigma_{1}-\sigma_{3}$ decrease. According to the third failure criterion, the value of $\sigma_{1}-\sigma_{3}$ decreasing indicates underground cavern stability increases.

4) Cavern is $80 \mathrm{~m}$ deep underground, and the surrounding rock is almost un-weathered, integrity high, with $170 \mathrm{MPa}$ uniaxial compressive strength. The FEM calculation shows the maximum stress of rock mass is $25.7 \mathrm{MPa}$, which is much less than $170 \mathrm{MPa}$, so it can determine the cavern is in safe conditions.
5) According to field convergence observations, underground cavern did not overall collapse. So field practice proves that overlying slag-piled does not affect underground works’ stability.

\section{REFERENCES}

[1] Zhou Nianqing, Yang Nan, Tang Yaqi. Determination of mechanical parameters of rock mass in nuclear power engineering site based on Hoek-Brown criterion [J]. Journal of Jilin University: Earth Science Edition, 2013, 43 (5): 1517-1522.

[2] Sheng Jia, Li Xiangdong. Determination method of rock mechanics parameters based on Hoek-Brown strength criterion [J]. MINING TECHNOLOGY,2009, 9(2).

[3] Hao Zhe, Wan Mingfu, LiuBin. Backward Analysis of Physical and Mechanical Parameters of Surrounding Rock of Hanjialing Tunnel [J].JOURNAL OF NORTHEASTERN UNIVERSITY(NATURAL SCIENCE), 2005, 26(3).

[4] Zahng Chuanqing, Feng Xiating, Zhou hui. Study of some problems about application of stress release method to tunnel excavation simulation [J]. ROCK AND SOIL MECHANICS, 2008, 29(5).

[5] Shao Jianguo, Zhuo Jiaoshou. Research on analysis method and criterion of rockmass stability [j]. Chinese journal of rock mechanics and engineering,2003, 22(5).2013, (2)35-37.

[6] Shan Yanjing, Cui Junzhi, Liang Fugang. Expected slide path method for stability analysis of rock mass based on statistics model of joints and stress field [j]. Chinese journal of rock mechanics and engineering,2002, 21(2). 